\title{
A Study on Optimal Resource Allocation of Taxis
}

\author{
Xiaopeng L $v^{1, a}$, Xinyuan Ding ${ }^{2}$ and Xian Chen $^{3}$ \\ ${ }^{1}$ Beijing Normal University, Zhuhai, Zhuhai Guangdong, China \\ ${ }^{2}$ Beijing Normal University, Zhuhai, Zhuhai Guangdong, China \\ ${ }^{3}$ Cardiff University, Cardiff, Wales, The UK
}

\begin{abstract}
As taxis play an increasingly important role in urban traffic system, the research on the supply and demand of taxis and the design of an optimal model of taxis supply has an importantly practical significance. In this paper, we used the traffic bureau data of Guangzhou, and determined the rate of empty driving as the index to establish the model. Nonlinear programming method was uesd to establish the optimal model of taxis quantity to meet the maximum income and maximum passenger satisfaction. Finally we got the optimal number of taxis was 37537.59
\end{abstract}

Key words: Taxi, supply and demand, nonlinear programming.

\section{Introduction}

In recent years, the city taxi has become an important means of transport in the public transport system, it has some feature like convenient, time-saving, which get more and more young pro-Lai. Since the 1990s, under the relevant policy support, the taxi industry develop rapid, but in many medium-sized cities, due to lack of corresponding planning and urban taxi formal management, resulting in a high rate of empty driving and road jams. In addition, the approach of taxi services unhealthy and bad habits of commuters, and also a serious impact on city traffic. Although some cities taken some control measures, but most of them are lack of practical experience. Therefore, its significance that studying the supply and demand taxi and establish a model of optimal taxi supply and demand to alleviate traffic congestion and improve urban planning.

Guangzhou located in the southeast coastal areas of our country, adjacent to Hong Kong and Macao, the located advantage is obvious, since the reform and opening up, Guangzhou's economic developing rapidly, the service sector's proportion rapidly increasing in regional GDP, the corresponding urban development more mature, transportation usher the peak period of development. This paper will use Guangzhou taxi industry as the research object, by analyze data and establish optimization model, study the model of Guangzhou optimal taxi supply and demand in the two dimensions of space and time.

\section{Problem situation}

The modern economic growth was actually the change of economic structure, was main caused by the revolution of services industry which was represented by the transportation and communications. In the future economic development, transportation industry will become a pillar industry in the service industry.

BIAN Yang etc. (2006) consider the social and individual interests while building multi-objective function model, case analysis shows that the model can determine the taxis' split rate, and provide theoretical basis for transport policy decisions ${ }^{[1]}$. BIAN Yang etc (2007) to build the model of network equilibrium of city's taxi to determine a reasonable scale of development of the city Taxi, and performance behaviors objectively in the driver search off, by using passengers' waiting time to determine a reasonable scale of development of the city $\operatorname{taxi}^{[2]}$. LI Hong-yanetc (2007) establish the index system and its analytical method of taxis' travel characteristics, time's distribution of travel and the spatial distribution of travel. And using the example of Suzhou City, analyzes the characteristics of taxis' trip in each time, giving the quantitative basis for decision making for reference to taxi operators and urban traffic management ${ }^{[3]}$. ZHOU Jing etc (2000) obtained the proportion of the system Kongshi taxi cab and passenger under certain conditions in the macro point of view. From the microscopic point of view, using queuing theory analyzed the busy of site of taxi ${ }^{[4]}$. LUO Duan-gaoetc (2009) established the model of urban taxis' network's equilibrium under the influence of distributed demand, and designed the algorithm to solve

\footnotetext{
${ }^{a}$ Xiao peng Lv: 270464440@qq.com
} 
the mode by using its' characterized. Its analysis results, can be determined reasonable scale development of urban taxi according to the passenger waiting time, and providing city taxi network planning and scientific basis of management ${ }^{[5]}$. MA Wu-bingetc(2014) proposed to use Hidden Markov theory to the model of trajectory of city taxi movement, constructed taxi motion model by analyze the actual data, predict the node position of probability distribution by calculating the model, and provide route suggestions ride support to different needs of users be basis on this model ${ }^{[6]}$.

\section{Index selection}

Establish a rational analysis the taxi resource supply and demand matching degree in different indicators of time and space is important for the accuracy of establishment of a subsequent optimization model. we use empty rate as a measure of indicators for analysis. Empty rate is the empty of mileage's proportion of the total running. As empty rate higher, the effect is more enough for the vehicle, operating income decrease in the same mileage, operating costs increase, the formula is empty stroke / total stroke $\times 100 \%$. Integrating the three factors that is the utilization of mileage, load factor of vehicle, taxi quantity of per thousand people, this paper define the new expression of empty rate, as follows: Empty Rate $=1-$

\section{Total Stroke in Each Day}

$\overline{n \times \text { Attendance of Taxi } \times \text { Stroke of Each Taxi in a Day }}$

According redefined empty rate formula, the first calculation is the total mileage of the average daily passenger of molecule item, to consider the issue from a combination of the two dimensions of space and time, According to Sort of GDP, as well as the distance of District of Guangzhou City from the Guangzhou municipal government, the paper divided these two spaces in space. At the same time, in the time dimension, we define weekdays, weekends and holidays these three variables as a time period of our analysis

\section{Data analysis}

District of Guangzhou City from 2015 GDP data, the largest GDP of total area is 3011.12 in Tianhe District, The total economy of Yuexiu District, and Huangpu District followed by it. The lowest total economic output is the 317.07 from Cong Hua District. According to the total amount of GDP of District of Guangzhou City, which divide Guangzhou City into the fourth ring.

Central District I: Yuexiu District, Tianhe District, Huangpu District, Central District II: Haizhu District, Baiyun District, Panyu District, Fringe District I: Liwan District, Huadu District, Nansha District, Fringe District II: Cong Hua District.

For total mileage of average daily passengerin different time and space, this paper according to the district population, employment and travel conditions of the Statistical Yearbook of Guangzhou, based on employment and GDP, calculate proportionally the number of trips and travel intensity,

Table 1. Travel situation of different area residents

\begin{tabular}{|c|c|c|c|c|c|}
\hline & \multicolumn{2}{|c|}{ Central District } & \multicolumn{2}{c|}{ Fringe District } & \multirow{2}{*}{ Total } \\
\cline { 2 - 5 } & I & II & I & II & \\
\hline $\begin{array}{c}\text { number } \\
\text { of } \\
\text { people }\end{array}$ & $\begin{array}{c}30480 \\
22\end{array}$ & $\begin{array}{c}55466 \\
41\end{array}$ & $\begin{array}{c}314021 \\
4\end{array}$ & 593415 & $\begin{array}{c}123282 \\
92\end{array}$ \\
\hline $\begin{array}{c}\text { Number } \\
\text { of trips }\end{array}$ & $\begin{array}{c}15652 \\
50\end{array}$ & 28366 & $\begin{array}{c}161259 \\
4\end{array}$ & 304736 & $\begin{array}{c}351094 \\
6\end{array}$ \\
\hline $\begin{array}{c}\text { Trip } \\
\text { times }\end{array}$ & $\begin{array}{c}34664 \\
849.4\end{array}$ & $\begin{array}{c}33471 \\
759\end{array}$ & $\begin{array}{c}167634 \\
04\end{array}$ & $\begin{array}{c}275463 \\
.2\end{array}$ & $\begin{array}{c}851754 \\
76.8\end{array}$ \\
\hline $\begin{array}{c}\text { Trip } \\
\text { intensity }\end{array}$ & $\begin{array}{c}11.372 \\
9\end{array}$ & 6.0346 & 5.3383 & 0.4642 & 23.21 \\
\hline
\end{tabular}

Table 2. Travel situation of residents in different periods

\begin{tabular}{|c|c|c|c|c|}
\hline & population & $\begin{array}{c}\text { Number } \\
\text { of trips }\end{array}$ & Trip times & $\begin{array}{c}\text { Trip } \\
\text { intensity }\end{array}$ \\
\hline workdays & 6275101 & 6275101 & $\begin{array}{c}20218187 . \\
17\end{array}$ & 3.22197 \\
\hline weekend & 12328292 & 1972527 & $\begin{array}{c}3934574.3 \\
92\end{array}$ & 0.31915 \\
\hline holiday & 17167580 & $\begin{array}{c}1687101 \\
4.32\end{array}$ & $\begin{array}{c}2950248.6 \\
23\end{array}$ & 0.17185 \\
\hline
\end{tabular}

We can saw clearly that the strength of travel of the central area is significantly higher than the strength of travel of the marginal zone from Table I Residents of different regions of Guangzhou travel case, but also the strength of travel of the central area 1 Guangzhou travel was significantly higher than the strength of central area 2 , the travel intensity of Fringe 1 was significantly higher than Fringe 2. So the supply of taxi should be allocated by accordance with travel intensity level of each region. We can know Travel intensity of workdays of residents of Guangzhou is most in Table II Travel case of Guangzhou residents in different time, then, Saturday and Sunday, holiday travel intensity is lowest.

Structural modes of travel are related to characteristics of mode of transportation, urban form and land layout and policies of traffic management, so the travel structural mode of different urban transport system is different. Based on the number of population in each districts of Guangzhou, people travel intensity, the rate of taxi's use andrateof choosing taxi, daily mileage data and using GDP to calculated proportionally daily total passenger miles of District of Guangzhou and the total number of passenger miles in three time periods daily.

Table 3. Average daily passenger in different time and space

\begin{tabular}{|c|c|c|c|}
\hline Central District I & $259 \times 10^{5}$ & workday & $344 \times 10^{5}$ \\
\hline Central District II & $137 \times 10^{5}$ & weekend & $341 \times 10^{5}$ \\
\hline Fringe District I & $122 \times 10^{5}$ & holiday & $183 \times 10^{5}$ \\
\hline Fringe District II & $106 \times 10^{5}$ & & \\
\hline
\end{tabular}


From table 3 Total miles of daily average passenger in different time and space, we can see, Total miles of daily average passenger of central area and workdays are greater than Total miles of daily average passenger of other time and space. Total miles of daily average passenger and positive correlation between economic, but also the impact is a two-way relationship, more total miles of daily average passenger in one time, the time create more in economic.

\section{Establishment and solution of model}

Then forecast the optimal number of taxis, if the fees of taxi and oil prices are fixed, the "optimal" of taxi should be reflected in these two following aspects: (1) for taxi ride passengers, the degree of satisfaction is the higher, the better; (2) for every taxi, the annual profit as the more, the better. By Analyzing the relationship between empty rate $i$, passengers' satisfaction $\mathrm{S}$, every taxis' annual profit $\mathrm{R}$, number of taxis in city $\mathrm{n}$, to establish the optimization model. Symbols as follows:

Variable: i: empty drive rate; R: annual profit of taxi; $n$ : the number of city taxi; pr: profit rate

Constant: co: average per taxi annual expenditure; re: industry annual total revenue; or: Taxi attendance; ad: average daily passenger total mileage; pd: average daily mileage per vehicle

For the time when the taxi number of "optimal" means rate of empty driving, passengers ride car easier, the satisfaction of passengers is also higher. Therefore, this article assumes that passenger satisfaction is uniquely determined by the rate of empty driving, and along with empty rate increases. For the mathematical model of empty rate iis:

$i=1-$

Total Stroke in Each Day $\overline{n \times \text { Attendance of Taxi } \times \text { Stroke of Each Taxi in a Day }}$ Mathematical model of earnings R per taxi:

$$
\begin{aligned}
R & =\frac{\text { Industry annual total revenue }}{n} \\
& - \text { Average annual expenditure per vehicle }
\end{aligned}
$$

The annual average costs include of operating costs fixed expenses and fuel consumption on. According to the research analysis of supply relationship between domestic and foreign by China Taxi Association of Cities, rate of empty driving of Urban Taxi and traffic relationship between demand and supply has the following:

Table 4. Empty driving rate and the traffic supply and demand

\begin{tabular}{|c|c|c|c|}
\hline $\begin{array}{c}\text { empty drive } \\
\text { rate }\end{array}$ & $\leq 25 \%$ & $\approx 30 \%$ & $\geq 40 \%$ \\
\hline state & $\begin{array}{c}\text { Obviously } \\
\text { in short } \\
\text { supply }\end{array}$ & $\begin{array}{c}\text { Basic } \\
\text { saturation, } \\
\text { balance of } \\
\text { supply and } \\
\text { demand }\end{array}$ & $\begin{array}{c}\text { Obvious } \\
\text { oversupply }\end{array}$ \\
\hline
\end{tabular}

Based on consideration of the state of supply and demand, which we determine the rate of empty driving range $0.3 \leq i \leq 0.4$ According to the report of taxi industry cost supervision and examination announced in 2015 by Guangzhou Municipal Price Bureau, can calculate the Guangzhou taxi companies profit margin is $13 \%$ at that time. In consideration of taxi companies and taxi drivers, we only determine the profits $p r \geq 10 \%$ is passable. Based on the above analysis, establish optimization model:

Max $S ; \mathrm{R}$

$$
\begin{gathered}
\text { s.t } i=1-\frac{A d}{n \times O r \times P d} \\
R=\frac{\operatorname{Re}}{n}-C o \\
S=S(i) \\
\frac{d S}{d I} \geq 0 \\
0.3 \leq i \leq 0.4 \\
\operatorname{Pr} \geq 10 \%
\end{gathered}
$$

As we can see from the above equation, passenger satisfaction $\mathrm{S}$ and taxis annual profit $\mathrm{R}$ are two conflicting requirements, so it has important practical significance to the optimal model while for allowing passenger satisfaction and annual earnings optimal at the same time. Model Solution:

1. Describe the satisfaction and its relationship of the rate of empty driving:

We use the number between 0 and 1 describe the passenger satisfaction, the highest satisfaction is 1 , the lowest satisfaction is. At the same time, this paper argues that the passenger satisfaction can describe uniquely empty rat, and it is assumed that:

(1) When empty rate is more than $40 \%$, the market presents the apparent oversupply state, the passengers can gets on the taxi easily, passenger satisfaction close to 1 .

(2) When empty rate is $30 \%$, the market is basically saturated, passengers can take the taxi, but need to wait a little time, the passenger satisfaction is 0.8 ;

(3) When empty rate is $25 \%$, the market is in short supply, passengers is difficult to take a car, passenger satisfaction less than 0.6 , with reduction of empty rate, passenger satisfaction index fell sharply.

In this paper, SPSS is used to fit the data, and the goodness of fit is determined as the three curve function. So, when the driving rate is $0 \leq i \leq 0.4$, the function relationship of rate of empty driving and passenger satisfaction:

$$
S(i)=5.714 \times 10^{-4}-3.980 i+39.455 i^{2}-58.133 i^{3}
$$

2. The relationship between customer satisfaction and taxi number

According to the Bureau of transportation statistics, Guangzhou taxi-operating conditions are as follows:

Table 5. Guangzhou taxi status table

\begin{tabular}{|c|c|c|c|c|c|}
\hline project & $\begin{array}{c}\text { Number } \\
\text { of taxi } \\
\text { companies }\end{array}$ & $\begin{array}{c}\text { Taxi } \\
\text { number }\end{array}$ & $\begin{array}{c}\text { Daily } \\
\text { operating } \\
\text { income }\end{array}$ & $\begin{array}{c}\text { Monthly } \\
\text { operating } \\
\text { income }\end{array}$ & $\begin{array}{c}\text { Mileage } \\
\text { utilization }\end{array}$ \\
\hline data & 84 & $\begin{array}{c}33 \\
\text { thousand }\end{array}$ & $\begin{array}{c}650 \\
\text { yuan/car }\end{array}$ & $\begin{array}{c}19500 \\
\text { yuan/car }\end{array}$ & $73.79 \%$ \\
\hline
\end{tabular}




\begin{tabular}{|c|c|c|c|c|c|}
\hline project & $\begin{array}{c}\text { Operating } \\
\text { mileage }\end{array}$ & Fuel cost & $\begin{array}{c}\text { Vehicle } \\
\text { fee }\end{array}$ & $\begin{array}{c}\text { Driver } \\
\text { income }\end{array}$ & $\begin{array}{c}\text { Taxi } \\
\text { attendance }\end{array}$ \\
\hline data & $\begin{array}{c}400 \\
\text { mile/day }\end{array}$ & $\begin{array}{c}5328 \\
\text { yuan/ } \\
\text { month }\end{array}$ & $\begin{array}{c}9300 \\
\text { yuan/ } \\
\text { month }\end{array}$ & $\begin{array}{c}2436 \\
\text { yuan/ } \\
\text { month }\end{array}$ & $85 \%$ \\
\hline
\end{tabular}

According to the table data, the calculation of the empty drive ratio is:

$$
i=1-\frac{132.1 \times 10^{5}}{n \times 0.8 \times 400}=1-\frac{41250.2}{n}
$$

The relationship between the number of taxis and the customer satisfaction of the formula(3) into formula(2) is as follows:

$$
\begin{aligned}
S(i)= & 5.714 \times 10^{-4}-3.9801 \times\left(1-\frac{41250.2}{n}\right)+39.455 \\
& \times\left(1-\frac{41250.2}{n}\right)^{2}-58.133 \times\left(1-\frac{41250.2}{n}\right)^{3}
\end{aligned}
$$

3. The relationship between the annual profit of the taxi and the number of taxiIndustry annual total revenue: $650 \times 365 \times 3.3=782925$ thousand yuan car fuel costs: $5328 \times 12=63.936$ thousand yuan Contract cost per vehicle $9300 \times 12=111$.6thousand yuan

We can get the profit $\mathrm{R}$ of a taxi for a year:

$$
R(n)=\frac{78292.5}{n}-(11.16+6.3936)
$$

4 the relationship between taxi profit and passenger satisfaction

Attention to the relational expression (4) between customer satisfaction and the number of taxis, $s(n)$ is monotone decreasing by $\mathrm{n}$; which is taxi relational expression (5) of the profit of taxi and the number, $\mathrm{R}$ (n) reduced with the increase of $\mathrm{N}, \mathrm{R}$ and $\mathrm{s}$ are irreconcilable. In order to achieve the optimal value of $\mathrm{R}$ and $\mathrm{S}$, the $\mathrm{N}$ in (5) is brought into (4) by R, and the relationship between $\mathrm{S}$ and $\mathrm{R}$ is obtained:

$$
\begin{aligned}
S(i)= & 5.714 \times 10^{-4}-3.9801 \times\left(1-\frac{41250.2}{\frac{78292.5}{R+17.5536}}\right) \\
& +39.455 \times\left(1-\frac{41250.2}{\frac{78292.5}{R+17.5536}}\right)^{2}-58.133 \\
& \times\left(1-\frac{41250.2}{\frac{78292.5}{R+17.5536}}\right)^{3}
\end{aligned}
$$

5 . Determination of the optimal number of taxis in Guangzhou City

The model of load rate requirement is $0.3 \leq i \leq 0.4$ by formula (2) can get the satisfaction $S$ of should meet $0.788571 \leq S \leq 1.0$ And because the requirements of profit margin by model is $\operatorname{Pr} \geq 10 \%$, according to basic hypothesis of annual expenditure per vehicle unchanged, annual profit $R \geq c o \times 10 \%=1.75536$ yuan . By formula (6), we can get the satisfaction of $\mathrm{S}$ easily should be consistent with $S \leq 0.8856$. According to formula (4) to the relationship between the satisfaction and taxi, at this time, using MATLAB inverse solve the scope of the taxi number $\mathrm{n}$ is (because it is a cubic equation, so each calculation results are three numerical value, according to the number of actual number of 33 thousand taxi, we give away the actual value of the phase difference of another numerical)

\section{$37414.75 \leq n \leq 37660.43$}

That is to say, in the reference of Guangzhou city travel data, the number of city's taxis should best control in the range in 2015, the average value is:

$$
n=37537.59
$$

6 . The central region, the edge region and the time interval of the optimal number of taxi

Different time and space only change the number of taxi passenger, we still use this model, then $d_{x}, e_{x}$ express regional center, edge area and the number of taxi passenger and turnover of different time intervals, as follows:

Table 6. The matching degree in different time and space

\begin{tabular}{|c|c|c|c|c|}
\hline & $\begin{array}{c}\text { Central } \\
\text { District I }\end{array}$ & $\begin{array}{c}\text { Central } \\
\text { District II }\end{array}$ & $\begin{array}{c}\text { Fringe } \\
\text { District I }\end{array}$ & $\begin{array}{c}\text { Fringe } \\
\text { District II }\end{array}$ \\
\hline workdays & 1.495 & 0.793 & 0.702 & 0.061 \\
\hline weekend & 0.148 & 0.0786 & 0.07 & 0.006 \\
\hline holiday & 0.08 & 0.042 & 0.037 & 0.003 \\
\hline
\end{tabular}

\section{Conclusion}

Urban taxi traffic is an important part of urban public transport.If the taxi number is too much, which results in a waste of public resources, and if there are too little taxis that will cause inconvenience to the public. These are different degrees of restricting the taxi industry healthy, stable and harmonious development.Finding the balance between the two is the focus of this paper.Through the reasonable analysis of the different time and space residents travel intensity, the optimization model is established to achieve the best matching degree of supply and demand, which provides a scientific, reasonable and feasible basis for the management department.

\section{References}

1. Y. Bian, W. Wang, J. Lu, J. Ma, Urb. T. T. M. S. R. P. Met, T. S. Eng. Inf. J. 1, 95 (2006).

2. Y. Bian, W. Wang, J. Lu, A B. Mod. Urb. T. Ope. Net, J. Tra. Tran. Eng. J. 1, 93 (2007).

3. Y. Li, Z. Yuan, H. Xie, S. Cao, X. Wu. Ana, T. Tri. C. Bas T. OD. Dat, Tra. Tran. S. Eng. Inf. J. 5, 85 (2007).

4. J. Zhou, J. He, Z. Sheng. R, Ana. C. T. Ope. S, J. Man. Eng. J. 1, 63 (2000)

5. G. Luo, F. Shi, Urb. T. Ope. B. Mod. C. Dem. Dis, J. Rai. Sci. Eng. J. 1, 87 (2009).

6. W. Ma, M. Liu, H. Huang, S. Deng, C. Urb. T. Mov. P. Mod. Bas. His. L, J. Nat. Uni. Def. Tec. J. 3, 129 (2014). 